Special example :-

1 $23 \times 456 \times 789$
I 23
456
789

First figure. $-3 \times 6 \times 9=162 \ldots . . . .2$ Second figure. $-16+2 \cdot 6 \cdot 9+5 \cdot 9 \cdot 3+8 \cdot 3 \cdot 6=403 \cdot 3^{2}$ Third figure. $-40+1 \cdot 6 \cdot 9+4 \cdot 9 \cdot 3+7 \cdot 3 \cdot 6+2 \cdot 5 \cdot 9$

$$
+5 \cdot 8 \cdot 3+8 \cdot 2 \cdot 6=634 \cdot . \cdot . \cdot 432
$$

Fourth figure. $-63+\mathbf{I} \cdot(5 \cdot 9+8 \cdot 6)+4 \cdot(2 \cdot 9+8 \cdot 3)$ $+7 \cdot(2 \cdot 6+5 \cdot 3)+2 \cdot 5 \cdot 8=593 \cdot \cdot \cdot 3432$

Fifth figure. $-59+1 \cdot 4 \cdot 9+4 \cdot 7 \cdot 3+7 \quad$ 1. 6 + I. $5 \cdot 8+4 \cdot 8 \cdot 2+7 \cdot 2 \cdot 5=395 \cdot \cdot 53432$

Sixth figure. $-39+\mathbf{I} \cdot 4 \cdot 8+4 \cdot 7 \cdot 2+7 \cdot \mathbf{I} \cdot 5=162 \cdot 253432$ Seventh and eighth figures. $-16+1.4 \quad 7=44 \quad . \quad 44253432$

Vienna, VI., Matrosengasse 8.

K. HAAS.

\section{The Migration of the Lemming.}

HAVING resided during the summer months for more than twenty years on the plateau from which the migrations of the Norwegian lemming are supposed by many to take their origin, I can speak from personal observation. Some years ago $I$ had the honour to read a rather lengthy paper before the Linnean Society on these animals, and, with one exception, to which reference will be presently made, I am happy in having nothing to alter or recant. The increase of the Lemmings is not cumulative, but rather periodic, as indeed is usual among the voles as well as among many other forms of life. The migrations are not caused by insufficient food now, whatever they may formerly have been, and this is evident from the fact that the swarms pass through, but do not exhaust the fertile districts which they encounter on their nilgrimage. Nor are they affected by any personal struggles between these most pugnacious of animals, for the young litters, when reared, go singly on the journey from which none have ever been observed to return. They do not follow the watershed, and they do not always migrate to the west-an error into which I was betrayed by trusting to common report and insufficient personal experience. But they do go straight. It is well known that the eyes of the lemming are so placed on the top of the head as to render it impossible for the animal when swimming, to discern any object not far above the plane of its horizon. On a calm morning last summer, I often placed my boat in the path of the swimmers, and noticed that they crossed my lake in an absolute "bee-line," and that they could not discern my presence until the angle subtended by the boat was infinitely higher than that of the opposite shore. This latter migration was soutb-east, and in the late autumn the steamer on Lake Mjosen made its way through thousands of these hapless wayfarers; whilst, still later, large numbers were to be seen close to Christiania ; but I venture to prophesy that none will be found in that neighbourhood next year, nor, for t te matter of that, in Heimdalen itself, though it is obvious that some must remain. Probably the ex. planation of these apparently capricious and suicidal migrations may be that they are the result of hereditary instinct, which formerly was of service if not necessary to the species. The straight course which they pursue must be owing to the sense of direction common to migrants, and I would hazard the conjecture that the changes of destination may be due to an instinct which, owing to its present inutility, is gradually diminishirg in precision and intensity.

Asgard, Richmond, December 24.

The Recent Earthquake in Japan.

Dans la lettre de M. J. Milne, Tokio, 7 novembre, sur le tremblemènt de terre du Japon du 28 octobre, 1891 (NATURE, xlv. 127), il y a entr'autres un fait intéressant : c'est la mise en oscillation de l'eau d'un bassin de 60 pieds de longueur sur 25 pieds de profondeur. Il est rare que dans un tremblement de terre l'eau des élangs ou des lacs soit mise en mouvement; le rythme des vibrations du sol ne correspond pas, le plus souvent, au rythme de l'oscillation de l'eau. Dans le cas actuel, les vagues ayant atteint une hauteur de $3 \dot{a} 4$ pieds, il est certain que l'eau a pris un mouvement de balancement.

Le formule d'un tel mouvement d'oscillation pendulaire, si le bassin a un fond horizontal, est :

$$
\begin{aligned}
& t=\frac{2 l}{\sqrt{ } g h}, \\
& t=60 \text { pieds }=18 \cdot 29 \mathrm{~m} . \\
& h=25 \text { pieds }=7 \cdot 62 \mathrm{~m} . \\
& t=4.2 \text { secondes de temps. }
\end{aligned}
$$

Il serait intéressant de savoir si le rythme des vibrations du tremblement de terre à Tokio a correspondu à une durée aussi lente; ou peut-être à la moitié de cette durée, soit $2 \cdot{ }^{\prime \prime}$. Ce serait déjà des vibrations extraordinairement lentes pour un tremblement de terre.

Morges, 12 decembre.

F. A. FOREL.

\section{ON THE VIRIAL EQUATION FOR GASES AND VAPOURS.}

A LTHOUGH I had, some time ago, written to Lord Rayleigh to the effect that I did not intend to prolong the discussion of this question, it may perhaps be expected that I should say a few words with reference to Prof. Korteweg's paper in the last issue of NATURE.

I. I do not agree with Prof. Korteweg's statement that Van der Waals's method, if it could be worked out with absolute rigour, would give the same result as the direct method. There is but one way of dealing with the virial equation:-if we adopt it at starting we must develop its terms one by one, and independently. In this connection I may refer to Lord Rayleigh's statement (NATURE, 26/11/9i): "It thus appears that, contrary to the assertion of Maxwell, $p$ is subject to correction." I cannot admit that $p$ is "corrected"; it is not even changed either in meaning or in value. It is introduced as, and remains (at the end of any legitimate transformations of the equation) the value of the pressure on the containing vessel. This, of course, depends upon what is going on in the interior. Other terms in the virial equation, which happen to have the same factor, may be associated with $p$ for convenience ; they assist in finding its value, but they do not change its meaning, nor do they " correct" it.

2. I do not think that much aid can be obtained by analogy, at least in the present question, from the case of one-dimensional motion. For the latter may be looked on as virtually the to-and-fro motions between fixed boundaries of a number of particles, each of which keeps its speed for ever unchanged, except at the moments when two instantaneously pass through one another. From this point of view the result of Lord Rayleigh and of Prof. Korteweg follows at once. Make the particles mere points, and diminish their free range by the sum of their original lengths, and everything will go on practically as before. Can a corresponding statement be made for three dimensions? Again, there is in the onedimensional case a perfectly arbitrary set of speeds, which remains unchanged:- - there is nothing analogous to the beautiful statistical distribution of Clerk-Maxwell. And what would be the result if molecular forces were introduced?

3. Prof. Korteweg seems not to have noticed the following sentence in my second letter to Lord Rayleigh (NATURE, 29/10/9r, p. 628) :- "The true mode of getting a cubic here ... [i.e. in Prof. Korteweg's notation,

$$
\left.p_{1} v=\frac{1}{3} \Sigma\left(m u^{2}\right)\left(1+\frac{\beta}{v}\right)\right]
$$

is to write $\beta /(v-\gamma)$ instead of $\beta / \tau$. This can, to a certain extent at least, be justified; the other method

NO. I I 57 , VOL. 45$]$ 
can not." I had, originally, added a sentence to the effect that, if $\gamma$ be taken equal to $\beta$, Van der Waals's result would at once be obtained. But I struck it out as irrelevant, because the discussion turned mainly upon the question of the value of the free path at a volume nearly equal to the critical volume. Here Van der Waals expressly recognized that his $b$ must be diminished in value. From my point of view, $\beta$ (having been determined once for all) is unchangeable; while $\gamma$ is essentially less than $\beta$, possibly even negative.

Prof. Korteweg takes a different view, and says that the "true" formula is obtained by the process above hinted at:-i.e. by putting (with the preceding notation) $\gamma=\beta$.

4. Prof. Korteweg speaks of the equation written above as "quite worthless." But, in all this discussion, where the rival expressions differ only by the introduction or rejection of terms of the order $\beta^{2} / v^{2}$; which, according to Prof. Korteweg, make an equation "true" or "quite worthless" as the case may be :-are we not introducing an error, of that order at least, in calmly writing

$$
p_{1}=p+\frac{a}{v^{2}}
$$

instead of some such expression as

$$
p_{1}=p+\frac{a}{v(v+a)} ?
$$

We have, fortunately, one practical test at hand to help in the decision of such questions. The introduction of the form last written, certainly more likely to be approximate than the first, renders the "quite worthless" equation capable of at least fairly representing the results of Andrews. The "true" equation, we know, does not represent them.

Edinburgh, 21/12/91.

$$
\text { P. G. TAIT. }
$$

\section{ON THE RELATION OF NATURAL SCIENCE} TO ART.1

\section{I.}

$\mathrm{W}^{\mathrm{E}}$

are assembled to-day in annual commemoration of a man whose marvellous breadth of view and extraordinary variety of interests are each time a fresh surprise to us. It seems incredible that the same hand could have penned the "Protogea" and the State-paper adjudging the Principality of Neufchâtel to the King of Prussia; or that the same mind could have conceived the infinitesimal calculus and the true measure of forces, as well as the pre-established harmony and the "Theodicea." A closer examination, however, reveals a blank in the universality of his genius. We seek in vain for any connection with art, if we except the Latin poem composed by Leibnitz in praise of Brand's discovery of phosphorus. We need hardly mention that his "Ars Combinatoria" has nothing to do with the fine arts. In his letters and works, observations on the beautiful are few and far between ; once he discusses more at length the pleasure excited by music, the cause of which he attributes to an equable, though invisible, order in the chordal vibrations, which "raiseth a sympathetic echo in our minds." However, the world of the senses had little reality for Leibnitz. With his bodily eye he saw the Alps and the treasures of Italian art, but they conveyed nothing to his soul. $\mathrm{He}$ was indifferent to beauty; in short, we never surprise this Hercules at Omphale's distaff.

The same neglect, at least of sculpture and painting,

1 An Address delivered by E. du Bois-Reymond, M.D., F.R.S., at the annual meeting of the Royal Academy of Setences of Berlin in commemoration of Leibnitz, on July 3,1890 . Translated by his daughter. This Address was first printed in the weekly reports (Sitsungsberichte) of the Berlin Academy, then in Dr. Rodenberg's Dentsche Kundschau, and lastly it was Academy, then in Dr. Rodenberg's Dentsche $R$ nundschazt, and lastly it was
published as a separate pamphlet by Veit and Co., at Leipzig, 1891.

$$
\text { NO. I I } 57 \text {, VOL. } 45]
$$

strikes us in Voltaire, who as polyhistorian can in some measure compare with Leibnitz. We are obliged to descend as far as the third generation-that is, to Diderot in France, to Winckelmann and Lessing in Germanybefore we meet with a decided interest in the fine arts, and an appreciation of the part they play in the progress of civilization.

The period thus defined, though it excels in science, shows with few exceptions a falling-off in the fine arts. On considering the historical development of these two branches of human productiveness, we find no correspondence whatever between their individual progress. When Greek sculpture was in its prime, science scarcely existed. True, Lionardo's gigantic personality, which combines the immortal artist with the physicist of high rank, towers at the beginning of the epoch generally known in the history of art as the Cinquecento. Still, he was too far in advance of his age in the latter capacity to be cited as an example of simultaneous development in art and science ; so little that Galilei was born the day of Michael Angelo's death. The mutual development of art and science at the commencement of our century is, I believe, merely a casual coincidence; moreover the fine arts have since been at the best stationary, whereas science strides on victoriously towards a boundless future.

In fact, both branches differ too widely for the services rendered to science by art, and vice vers $\hat{a}$, to be other than external. " Nature," Goethe very truly observed to Eckermann-little thinking how harshly this remark reflects on part of his own scientific work-" Nature allows no trifling; she is always sincere, always serious, always stern; she is always in the right, and the errors and mistakes are invariably ours." Fully to appreciate the truth of this, one must be in the habit of trying one's own hand at experiments and observations, while gazing in Nature's relentless countenance, and of bearing, as it were, the tremendous responsibility incurred by the statement of the seemingly most insignificant fact. For every correctly interpreted experiment means no less than this: whatever occurs under the present circumstances, would have occurred under the same conditions before an infinite negative period of time, and would still occur after an infinite positive period. Only the mathematician, whose method of research has more in common with that of the experimenter than is generally supposed, experiences the same feeling of responsibility in presence of Nature's eternally inviolable laws. Both are sworn witnesses before the tribunal of reality, striving for knowledge of the universe as it actually is, within those limits to which we are confined by the nature of our intellect.

However, there is a compensation for the philosopher, labouring under this anxious pressure, in the consciousness that the slightest of his achievements will carry him one step beyond the highest reached by his greatest predecessor; that possibly it may contain the germ of vastly important theoretical revelations and practical results, as Wollaston's lines contained the germ of spectral analysis; that, at any rate, such a reward is not only in the reach of a born genius, but of any conscientious worker; and, finally, that science, by subduing Nature to the rule of the human intellect, is the chief instrument of civilization. No real civilization would exist without it, and in its absence nothing could prevent our civilization, including art and its master-works, from crumbling away again hopelessly, as at the decline of the ancient world.

This consciousness will also make up to the philosopher for the thoughtlessness of the multitude, who, while enjoying the benefits thus lavished upon them, hardly know to whom they owe them. The country rings with the name of every fashionable musical virtuoso, and cyclopædias insure its immortality. But who repeats the name of him who achieved that supreme triumph of the inventive intellect - to convey through a copper wire across 